\title{
Course of renal involvement in the short term in children with coronavirus disease 2019
}

\author{
Sandra M. Martin, M.D., ${ }^{a}$ Luciana Meni Battaglia, M.D., ${ }^{a}$ M. Laura Beaudoin, \\ M.D., ${ }^{a}$ M. Cecilia Torres Pérez, M.D. ${ }^{a}$ and Alejandro Balestracci, M.D. ${ }^{a}$
}

\begin{abstract}
Renal involvement among pediatric patients with coronavirus disease 2019 (COVID-19) ranges between $10 \%$ and $80 \%$. Given the limited information about its prognosis, the objective of this study was to describe the short-term course of patients in whom renal involvement was detected during hospitalization due to COVID-19.

This was an observational, cross-sectional study in patients aged 1 month to 18 years who had COVID-19 and renal involvement. Those with a known kidney disease were excluded. A total of 27 patients with renal involvement were identified; 14 of them were followed-up to study their disease course for 3 months after diagnosis. All of the patients had achieved normal plasma creatinine levels during hospitalization and, at the time of outpatient follow-up, which took place 145 days (92-193) later, all had normal blood pressure and urinary values, except for 1 patient who continued with microscopic hematuria. Course was favorable; in most patients, renal involvement had fully resolved.
\end{abstract}

Key words: COVID-19, acute kidney injury, child, prognosis.

http: / / dx.doi.org/10.5546/ aap.2021.eng.414

To cite: Martin SM, Meni Battaglia L, Beaudoin ML, Torres Pérez MC, Balestracci A. Course of renal involvement in the short term in children with coronavirus disease 2019. Arch Argent Pediatr 2021;119(6):414-418.

a. Unit of Nephrology, Hospital General de Niños Pedro de Elizalde, Autonomous City of Buenos Aires, Argentina.

E-mail address:

Sandra M. Martin, M.D.: smmartin265@gmail.com

Funding: None.

Conflict of interest: None.

Received: 5-24-2021

Accepted: 7-14-2021

\section{INTRODUCTION}

In December 2019, severe acute respiratory syndrome coronavirus 2 (SARS-CoV-2) was recognized as the causative factor of coronavirus disease 2019 (COVID-19), which has led to a pandemic. SARS-CoV-2 infection has a high prevalence of pneumonia, but it also affects other organs. ${ }^{1}$ In children, it usually has a favorable course compared to adults, and half remain asymptomatic. ${ }^{1}$ However, it may occur with multisystem involvement, including hyperinflammatory shock. ${ }^{1}$

The prevalence of renal involvement in children with COVID-19 ranges between $10 \%$ and $80 \%$, depending on the severity of their clinical condition. ${ }^{2-4}$ To the authors' knowledge, there are still no studies describing the course of these patients. Therefore, the objective of this study was to describe the course of renal involvement in the short term among patients hospitalized due to COVID-19.

\section{PATIENTS AND METHODS}

This was an observational, cross-sectional study that included patients hospitalized at Hospital de Niños Pedro de Elizalde between May and October 2020 who: a) had confirmed SARSCoV-2 infection and renal involvement, identified through a previous multicenter study aimed at assessing the prevalence of renal involvement in COVID-19, which required a minimum creatinine level and/or a urine test for inclusion; and b) were between 1 month and 18 years old. Identified patients were scheduled to study their renal course 3 months after diagnosis. Those with a known kidney disease were excluded.

The study was approved by the hospital's Ethics Committee, and a written informed consent and / or assent was obtained as applicable (protocol no. 3597-2021).

Renal involvement was defined as the presence of acute kidney injury (AKI), pathological proteinuria, hematuria, leukocyturia and / or arterial hypertension (HTN). During hospitalization, the following data were recorded: age, sex, previous diseases, clinical severity upon admission, admission to the intensive care 
unit (ICU), renal replacement therapy (RRT) requirement, creatinine, proteinuria, hematuria, leukocyturia, and blood pressure. During the outpatient renal follow-up, the following data were recorded: days since COVID-19 diagnosis, weight, height, creatinine in those who did not have a normal value at discharge, blood pressure, urinary sediment, and urine protein/creatinine ratio.

\section{Definitions}

SARS-CoV-2 infection: detected by polymerase chain reaction performed on nasopharyngeal aspirates or positive serology (IgM and / or IgG). ${ }^{3}$

Renal involvement was assessed based on the presence or absence of:

AKI: creatinine $(\mathrm{mg} / \mathrm{dL})>1.5$ times the upper value of normal for age. 3,5

Hematuria: > 5 red blood cells per highpowered field. ${ }^{6}$

Pathological proteinuria: presence of 1 or more crosses in the urine strip or urine protein/creatinine ratio on spot urine sample $>0.2 .7$

Leukocyturia: presence of $\geq 5$ white blood cells per high-powered field. ${ }^{8}$

HTN: systolic and/or diastolic blood pressure $\geq 95^{\text {th }}$ percentile and $<95^{\text {th }}$ percentile $+12 \mathrm{mmHg}$ for age, sex, and height in subjects younger than 16 years and systolic blood pressure between 140 and $159 \mathrm{mmHg}$ and / or diastolic blood pressure between 90 and $99 \mathrm{mmHg}$ in subjects older than 16 years (according to the guidelines of the National Program for School Health [Programa Nacional de Salud Escolar, PROSANE]). ${ }^{9}$

Clinical condition upon admission was defined as follows:

Asymptomatic: diagnosed through close contact tracing, no symptoms.

Mild: patients without risk factors, no oxygen therapy requirement or parenteral hydration with normal vital signs and non-specific symptoms.

Moderate: patients with respiratory distress, who require oxygen therapy and/or parenteral hydration or have mild conditions in a risk group.

Severe: patients with severe respiratory distress with clinical symptoms compatible with compensated septic shock.

Critical: patients with impending acute respiratory failure, decompensated shock or cardiorespiratory arrest. ${ }^{10}$

Multisystem inflammatory syndrome in children (MIS-C): children with fever for more than 3 days and 2 of the following: a) skin rash or bilateral conjunctivitis or signs of mucocutaneous inflammation; b) hypotension or shock; c) myocardial dysfunction, pericarditis, valvulitis or coronary artery anomalies; d) coagulopathy; and e) acute gastrointestinal symptoms, with elevated markers of inflammation. .11,12 $^{1}$

\section{Statistical analysis}

A descriptive analysis was done; continuous variables were expressed as median (range) because data did not have a normal distribution (ShapiroWilk test) and categorical variables were described as frequency of occurrence and/or percentage. The Statistix $7^{\circledR}$ software (IBM version, FL) was used.

\section{RESULTS}

In the study period, 435 patients with COVID-19 were hospitalized. After reviewing the medical records for the mentioned study, 346 cases were included (255 had mild and/or asymptomatic forms); of these, 27 (7.8\%) had renal involvement (Figure 1). Among the latter, 7 had previous diseases. The most frequent manifestation of renal involvement was proteinuria, observed in 17 cases, followed by microscopic hematuria in 8, leukocyturia in 7, and AKI in 2; no patient required RRT or developed HTN. All had achieved normal plasma levels during hospitalization, but they had no urine tests done before hospital discharge to determine whether the renal condition had completely resolved. To study their course, patients were contacted for an outpatient follow-up. Thirteen of them were not assessed: 11 were not located, 1 developed Henoch-Schönlein purpura at 3 months, and the other patient died 2 months later due to sepsis, with histiocytosis as an underlying condition (Figure 1). Therefore, renal course was assessed in 14 patients ( 8 males; median age: 5.2 years; range: $0.5-16.1$ ). In this subgroup, the distribution of renal involvement was as follows: proteinuria in 10 cases, leukocyturia in 6, microscopic hematuria in 3, and AKI in 1. Three patients had previous diseases and 4 of them developed severe forms (Table 1). The latter required admission to the ICU for 2.5 days (1-7) due to MIS-C, 1 required mechanical ventilation, 2 received inotropic agents, 1 developed AKI, and all had significant proteinuria. When patients were assessed in the outpatient follow-up, 140 days (92193) had elapsed since the onset of COVID-19. All continued having normal blood pressure and urinary findings returned to normal, except for 1 patient who still had microscopic hematuria (Table 1). 


\section{DISCUSSION}

The etiopathogenesis of renal involvement caused by COVID-19 is little-known and implies glomerular and tubular damage due to viral invasion in addition to an imbalance in the inflammatory and renin-angiotensin-aldosterone systems. ${ }^{13,14}$

Pediatric patients with COVID-19 have a more favorable course than adults, with a mortality rate of less than $1 \% .{ }^{1}$ By indication of the National Ministry of Health of Argentina, when the pandemic started, all patients were hospitalized, even if asymptomatic. The rate of renal involvement of hospitalized patients included in the previous multicenter study (not published) was $7.8 \%$. Among hospitalized adults, the rate of renal involvement is approximately $30 \%,{ }^{14}$ whereas in pediatrics it is variable. Stewart et al. ${ }^{3}$ observed in 52 children a prevalence of $77 \%$. On the contrary, and consistent with other pediatric series, ${ }^{1,2}$ in the patients included in this study, renal involvement was less frequent, probably because most had mild forms.
In relation to the type of renal involvement, among adults, significant proteinuria was observed in $40-60 \%$; hematuria, in $20-40 \%$; leukocyturia in 30\%; and AKI, in 15\%, with RRT requirement in $5 \%$ of cases. ${ }^{13,14}$ In addition, in pediatric patients, high creatinine levels were observed in $46 \%$; significant proteinuria, in $42 \%$; and microscopic hematuria, in $77 \% .^{3}$ In the patients included in this study, findings were mostly mild and non-specific and may have been caused by factors extrinsic to COVID-19. In them, as in adults, significant proteinuria prevailed. ${ }^{12,14}$

The course of renal involvement in pediatric patients with COVID-19 is uncertain. In this series, it was excellent, regardless of the severity of the disease. Actually, out of the 4 patients who had renal involvement and required admission to the ICU, all developed MIS-C and only 1 developed AKI but did not require RRT and achieved a normal renal function before hospital discharge. Stewart et al. ${ }^{3}$ observed that $38 \%$ of patients admitted to the ICU developed AKI (46\% with MIS-C) but did not require dialysis.

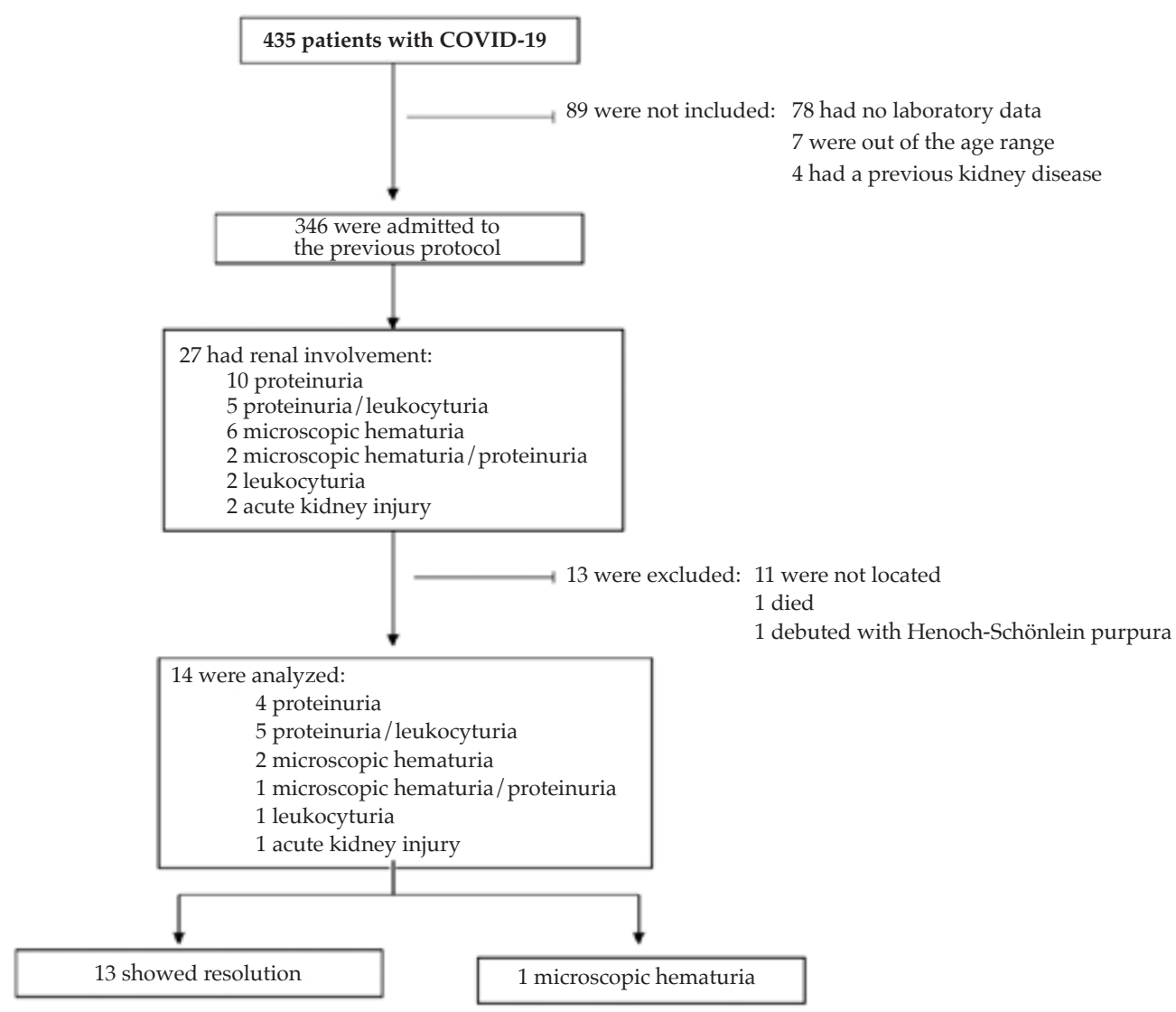




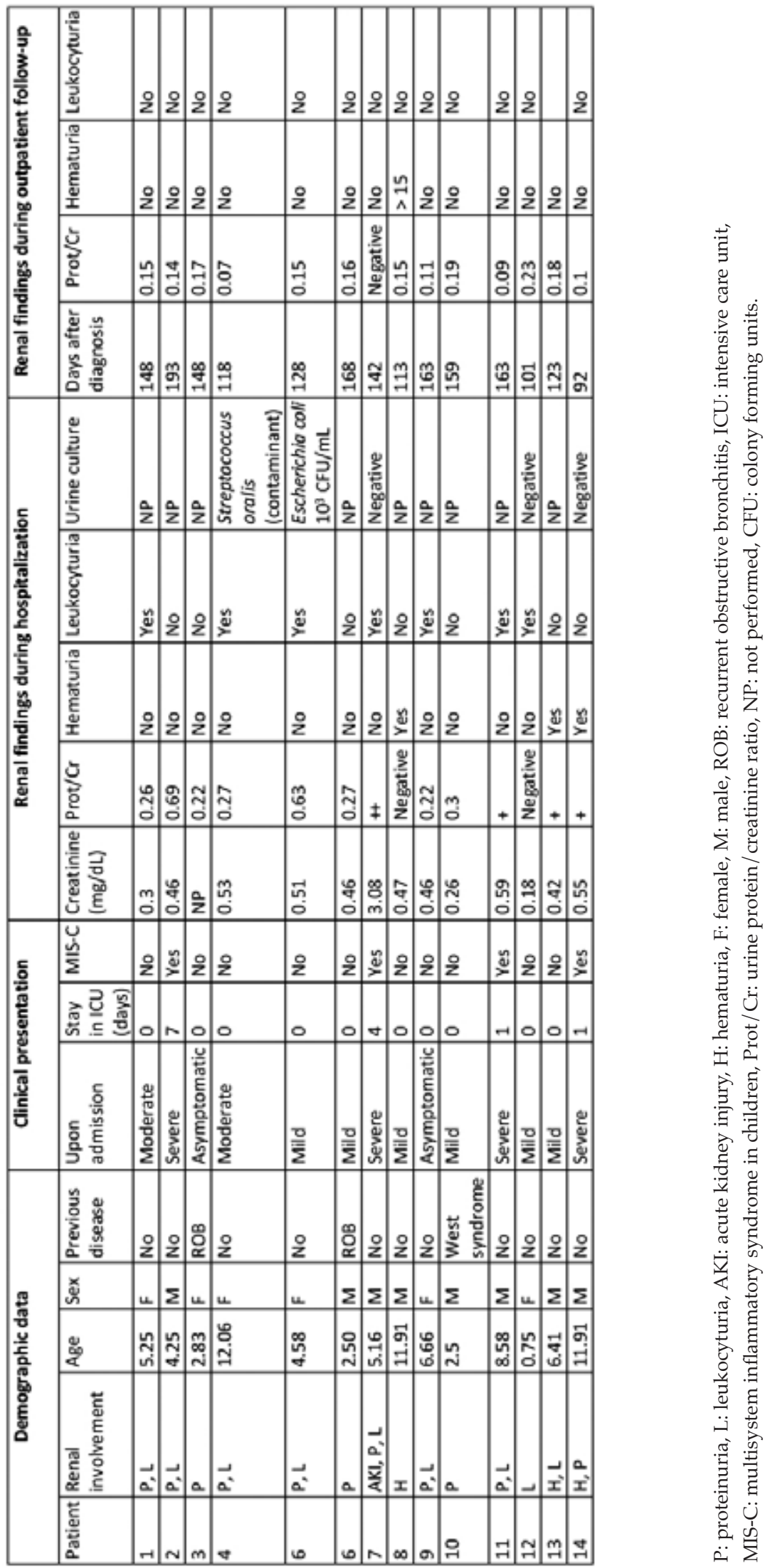


In patients with severe forms included in this study, like in the others, urinary findings resolved after 3 months, except in 1 who continued with microscopic hematuria. The presence of previous diseases did not worsen renal involvement either.

The limitations of this study were the small sample size, the high percentage of patients who were lost-to-follow-up, the scarce number of patients with severe forms studied, and the relatively short follow-up duration, since it is known that patients with AKI should receive follow-up in the long term. ${ }^{15}$ However, although findings should not be generalized, given the fact that this is a new disease, the information presented here may be clinically useful.

\section{CONCLUSION}

In most patients included in this study, renal involvement resolved completely in the short term. Further studies are required to corroborate these data.

\section{REFERENCES}

1. Qiu H, Wu J, Hong L, Luo Y, et al. Clinical and epidemiological features of 36 children with coronavirus disease 2019 (COVID-19) in Zhejiang, China: an observational cohortstudy. Lancet Infect Dis. 2020;20(6):68996.

2. Wang X, Chen X, Tang F, Luo W, et al. Be aware of acute kidney injury in critically ill children with COVID-19. Pediatr Nephrol. 2020; 36(1):163-9.

3. Stewart DJ, Hartley JC, Johnson M, Marks SD, et al. Renal dysfunction in hospitalised children with COVID-19. Lancet Child Adolesc Health. 2020; 4(8):e28-9.

4. Deep A, Upadhyay G, du Pré P, Lillie J, et al. Acute Kidney Injury in Pediatric Inflammatory Multisystem Syndrome Temporally Associated with Severe Acute Respiratory Syndrome Coronavirus-2 Pandemic: Experience from PICUs Across United Kingdom. Crit Care Med. 2020; 48(12):1809-18.

5. Kidney Disease: Improving Global Outcomes (KDIGO) Acute Kidney Injury Working Group. KDIGO clinical practice guideline for acute kidney injury. Kidney Int Suppl. 2012;2(Suppl 1): 1-138. [Accessed on: November $\left.15^{\text {th }}, 2020\right]$. Available at: https: / / kdigo.org/wpcontent/ uploads / 2016/10/KDIGO-2012-AKI-GuidelineEnglish.pdf

6. Moustafa FE, Eid R, Hamdy N. Pediatric glomerular hematuria: a clinicopathological study. Clin Exp Nephrol. 2020; 24(7):613-21.

7. de Lucas Collantes C, Izquierdo García E. Proteinuria.Protoc Diagn Ter Pediatr. 2014; 1:69-79.

8. Comité de Nefrología. Nuevas recomendaciones frente a las actuales controversias en infección urinaria: Resumen ejecutivo. Arch Argent Pediatr. 2015; 113(6):579-81.

9. Argentina. Ministerio de Salud. Interpretación y uso de las nuevas tablas de referencia de presión arterial para niños, niñas y adolescentes Programa Nacional de Salud Escolar (PROSANE).Enero 2020. [Accessed on: November $15^{\text {th }}, 2020$ ]. Available at: https://bancos.salud.gob.ar/sites/default/ files / 2021-04 / interpretacion-uso-nuevas-tablas-referenciade-presion-arterial-prosane-2020.pdf

10. Argentina. Ministerio de Salud. Estrategias de abordaje para la atención de la infección respiratoria aguda (IRA) pediátrica en el II y III nivel de atención en contexto de pandemia. Recomendaciones 29 demayo de2020. [Accessed on:November 15th, 2020] Availableat:https: / bancos.salud. gob.ar / sites / default / files / 2020-07 / covid19-estrategiasabordaje-infeccion-respiratoria-aguda-pediatrica-2y3-nivelpandemia.pdf

11. Argentina. Ministerio de Salud. Vigilancia, diagnóstico y manejo institucional de casos en pediatría. [Accessed on: November $\left.10^{\text {th }}, 2020\right]$. Available at: https://www. argentina.gob.ar/salud/ coronavirus-COVID-19/ casospediatria

12. Bustos B, Jaramillo-Bustamante JC, Vasquez-Hoyos P, Cruces P, Díaz F. Pediatric Inflammatory Multisystem Syndrome Associated With SARS-CoV-2: a case series quantitative systematic review. Pediatr Emerg Care. 2021; 37(41):44-7.

13. Gabarre P, Dumas G, Dupont T, Darmon M, et al. Acute kidney injury in critically ill patients with COVID-19. Intensive Care Med. 2020; 46(7):1339-48.

14. Nadim MK, Forni LG, Mehta RL, Connor MJJr, etal. COVID19-associated acute kidney injury: consensus report of the $25^{\text {th }}$ Acute Disease Quality Initiative (ADQI) Workgroup. Nat Rev Nephrol. 2020; 16(12):747-64.

15. Askenazi D, Feig D, Graham N, Hui-Stickle S, Goldstein SL. 3-5 years longitudinal follow-up of pediatric patients after acute renal failure. Kidney Int. 2006; 69(1):184-9.7. 